\title{
Delegação de Competência
}

\author{
Clenício da Silva Duarte
}

Consultor Jurídico do DASP

SUMÁRIO: 1. A descentralização e a desconcentração como necessidades na moderna técnica de gestão. A delegação de competência como a mais importante medida de desconcentração. 2. Conceito de delegação. Imprescindibilidade de lei formal para que ela ocorra. 3 . Especies de delegação, segundo a natureza material dos atos outorgados. Delegação de um para outro Poder (delegação de poderes) e delegação dentro do mesmo Poder (delegação legislativa e administrativa). 4. Distinção entre delegação, substituição e representação. 5. Natureza jurídica da delegação. Irresponsabilidade do delegante pelos atos do delegado. Delegação com e sem reserva de competência. Como autorização, a delegação é ato discricionário, revogável ao nuto do delegante. 6 . Impossibilidade de revogação pelo delegado dos atos do delegante, praticados anteriormente à delegação. Revogação dos atos do delegado pelo delegante na pendência da delegação. 7 . A mudança de titulares não acarreta necessariamente a caducidade da delegação que, para ser revogada, tem de haver ato expresso. 8. Pode o delegado subdelegar as atribuições que Ihe foram conferidas? 9. Requisitos da delegação. Atribuições indelegáveis. 10. A delegação no Direito Constitucional Brasileiro 11. Idem, na Lei de Reforma Administrativa. 12. Conclusão.

1. As múltiplas e cada vez mais absorventes tarefas que se cometem ao Poder Público, mormente nos dias de hoje, em que sua ação intervencionista mais e mais se acentua, impuseram a descentralização de atribuições, de modo a que se aparelhasse o Estado para lograr os seus objetivos, dentro da dinâmica administrativa, segundo os princípios mais modernos da técnica de gestão. Mas, dada essa pletora de atividades que o próprio Estado se atribuiu, nem sempre basta, para a realizaÇão eficiente e rápida de seus fins, o recurso à descentralização, porquanto, mesmo praticada esta em larga escala, sempre Se concentram, num dado órgão ou em determinadas autorida- 
des, tarefas tão numerosas que outro recurso não resta senão o apelo à desconcentração. Nem sempre essa desconcentração visa apenas a aliviar a carga de trabalho, sendo, muitas vezes, usada para maior eficiência do resultado a alcançar, pelas meIhores condições técnicas eventuais do órgão ou agente em favor do qual ocorreu a desconcentração. ${ }^{1} \mathrm{E}$ entre os atos de desconcentração se destaca, pela sua importância, a delegação de competência. ${ }^{2}$

2. A delegação, em Direito Público, ocorre sempre que se atribuem funções próprias do delegante a pessoa ou órgão, que se diz delegado, e que não teria essa competência ${ }^{3}$ se não se efetivasse a delegação. ${ }^{4}$ Como as atribuições dos órgãos que integram os três Poderes do Estado ou constam de disposições constitucionais ou, em certos casos, apenas de normas de lei ordinária, e, dentro de cada Poder, a fixação de competência das várias autoridades também decorre de preceituação legal, implícita ou explícita, segue-se que a delegação de competência só pode verificar-se por força de autorização de lei formal. 5

1. "O objetivo da delegaçăo, de fato, não é tanto o de permitir que o delegante se alivie do exercicio das próprias funções quanto o de que essas funções sejam exercidas, também, oportunamente e do melhor modo possivel" (FLAMINIO FRANCHINI, La Delegazione Amministrativa, Milăo, 1950, p. 34).

2. Para MARCELLO CAETANO, Manual de Direito Administrativo, Lisboa, 1968, 8 , a ed., vol. I, n. ${ }^{\circ} 110$, p. 246, "a desconcentraçăo pode ser originária, quando a própria lei dá competência aos chefes subalternos para tomar decisőes ou por delegaçăo de poderes ( $V$., adiante, no texto, referência à indistinção de denominaçăo), quando a competência é conferida por lei ao chefe superior mas com a faculdade de delegar poderes aos subalternos admitindo a lei por vezes que estes, por seu turno, subdeleguem em subalternos de segundo grau os poderes recebidos por delegaçăo".

3. Segundo RENATO ALESSI, Diritto Amministrativo, Milão, 1949 vol. I, ps. 102 e 103 "competència de um determinado órgåo e - subjetivamente - de um determinado funcionário é exatamente o complexo das atribuiçð̄es conferidas a co órgăo e ao funcionário titular. A competência, portanto, como uma medida de quantidade: que foi reconhecido no campo do direito processual, onde se concebe a competência como a medida da jurisdiçăo atribuida a um determinado órgăo jurisdicional. No campo administrativo, por conseguinte, a competéncia é a medida do poder de açăo que diz respeito a um determinado órgåo administrativo $e$, por isso, ao funcionário titular".

4. MARCELLO CAETANO, ob. e vol. cits., n. 0 100, p. 219 , assim define a delegaçăo: "A delegaçăo de poderes consiste no ato pelo qual um orgăo normalmente compe. tente para a prática de certos atos juridicos autoriza um outro órgão ou um agente, indicados por lei, a praticá-los também".

FLAMINIO FRANCHINI, Ob. cit., p. 12, a conceitua como "a transferência para outrem do exercicio de funçōes próprias". No mesmo sentido, HELY MEIRELLES, Direito Administrativo Brasileiro, 2.a ed., Rev. dos Tribunais, 1966, p. 69.

5. O poder de delegação só é de admitir-se "quando uma disposiçăo de lei o consinta" (DONATO DONATI, Principii di Diritto Amministrativo Scienza dell'Amministrazione, Cedam, 1932, 3. a ed., p. 97.

"A delegaçăo, .... como instituto juridico, é composta de dois atos, dos quais o primeiro, premissa maior para o desenvolvimento do segundo, é exatamente um ato normativo que estabelece uma competência (criando, entăo, ou aumentando outras vezes a esfera de atribuições).

Mas há também um segundo ato na delegação, o ato de outorga, própria ao delegante, e que este dirige ao delegado, permitindo, assim, por esse meio, que a competência se torne eficiente" (FLAMINIO FRANCHINI, ob. cit., p. 68),

Assim se expressa ALCINO PINTO FALCAO, Repertório Enciclopédico do Direito Brasileiro, vol. 15, p. 155, verbete Delegaçåo: "A doutrina dominante é no sentido de que só pode haver delegação quando expressamente autorizada pela norma positiva; a menos que se trate de competencia indistinta entre superior e inferior".

R. Serv. Públ., Brasília, 108 (1): jan/abr. 1973 
3. A delegação, consoante a natureza das atribuições outorgadas, pode verificar-se: a) de um para outro dos Poderes do Estado, e b) dentro do mesmo Poder, de uma autoridade ou órgão para outra ou outro de menor hierarquia. No primeiro caso, diz-se que há delegação de poderes; ${ }^{6}$ no segundo, ocorre delegação a ser classificada segundo a natureza material do ato a ser delegado.

É comum, entre os autores, indistinguir as denominações, não raro se expressando a delegação dentro de um mesmo Poder como delegação de poderes, ${ }^{7}$ quando esta tem sentido específico, pela extravasão de atribuições de um para outro Poder do Estado. Se o conceito de delegação de competência ou de atribuições é mais amplo, por isso que esta pode ser de um para outro Poder, ou dentro do mesmo Poder, a delegação de poderes só ocorre quando se verifica a outorga de atribuições, pelo delegante, fora do Poder em que ele se situa. Preferimos, assim, denominar delegação de competência ou de atribuições, como expressão genérica, que se subdividiria em duas espécies: a) delegação de atribuições de órgão de um para o de outro Poder, ${ }^{8}$ tradicionalmente conhecida por delegação de poderes, e b) delegação de atribuições dentro do mesmo Poder, quando a transferência de competência se efetiva de um órgão ou autoridade (o delegante) para outro ou outra de menor hierarquia (o delegado), mas sem sair da esfera de atuação do Poder a que pertencem. Esta última (b) pode classificar-se em: 1) delegação administrativa ${ }^{9}$ e 2) delegação legis-

6. "Essa teoria da delegaçăo de poder era, insiste-se em assinalar, a transferência pura e simples em direito administrativo de uma teoria de direito privado, a teoria pura e simples um como em outro caso, assistia-se a uma delegaçăo de poderes do mandato. Em um como em outro caso, assiste que o ato realizado pelo delegado tinha exatamente o mesmo caráter que o executado pelo delegante.

Essa teoria foi aceita sem discussăo pelos autores $\theta$ pela jurisprudência até - fim do século XIX. Mas a essa época apareceram, um após outro, dois artigos, um de M. ESMEIN, em 1894, outro de M. BERTHELÉMY, em 1898, pelos quais foi um de M. ESMEIN, em 1894, outro que o poder năo se pode delegar. Esses autores, estabelecendo a distinçăo entre os órgãos constituintes e os órgăos da Consres, estabelecendo a distinção entrón de competencia e de poderes feitas pela Constituiçăo năo podem ser modificadas fora de tempo e que um órgăo constituido Constituiçăo năo podem ser modificadas a outro órgão poder que the era peculiar" nenhuma qualidade tinha para delegar a outro odministrativo das Regras e Principios de Direito Privado, trad. de Paulo da Mata Machado, R.D.A., I, p. 472).

7. Cf., verbi gratia, MARCELLO CAETANO, ob. e vol. cits. n.os 100 e 110.

8. Năo só há delegaçăo de poderes do Legislativo para o Executivo. Também há casos, no direito alienigena, de delegaçăo de competência jurisdicional para órgăos administrativos (cf. BILAC PINTO, Parecer in R.D.A., vol. VI, p. 253).

9. A delegaçăo administrativa năo só ocorre dentro da esfera de atuaçăo do Poder Executivo, mas pode efetivar-se dentro de qualquer dos demais Poderes, como a transferéncia de atribuiçঠes materialmente administrativas de autoridade superior para a inferior do Poder Legislativo ou do Judiciário, sabido que no âmbito de atuaçăo desses Poderes se praticam atos materialmente administrativos, de que são exemplos os que o Presidente da Camara e do Senado e os dos Tribunais do País baixam em relação ao pessoal das Secretarias desses órgãos. Cl., ao propósito, nosso artigo, nesta Revista, vol. 105, n..$^{\circ}$, maio a agosto de 1970 , ps. 31 e segs., sob o titulo Os Regulamentos independentes. 
lativa, ${ }^{10}$ de acordo com a natureza material do ato objeto da delegação, isto é, quando se trata, do ponto-de-vista material, de ato administrativo ou legislativo ${ }^{11}$, respectivamente.

4. A delegação, lato sensu, não se confunde nem com a substituição nem com a representação. Isto porque, na delegação, se transferem ao delegado atribuições próprias do delegante, ao passo que, na substituição, ao substituto compete as atribuições do substituído, agindo aquele como se este fosse, e, na representação, o representante age em nome do representado, devendo depois prestar-lhe contas do mandato.

Na substituição, o substituto se investe dos poderes que correspondem ao substituído, como se ele, no momento em que a exerce, fosse o titular do cargo. $\mathrm{Na}$ delegação, não há substituição do titular, mas as atribuições deste (as que sejam objeto da delegação) é que se transferem para o delegado, que as exerce como se elas fossem inerentes ao seu cargo, isto é, as atribuiçc̃es objeto da delegação se acrescem às normais do cargo exercido pelo delegado. Na representação, o representan. te age em nome do representado, o que não ocorre na delegação, quando o delegado age em razão do seu cargo, a cujas atribuições se somaram as que constituem o objeto da delegação.

Na delegação, há uma relação de hierarquia ${ }^{12}$ entre delegante e delegado, o que não se verifica com a substituição, quando o substituto age como se fosse o substituído, nem com a representação, que é estranha também à relação hierárquica. $\mathrm{Na}$ substituição, o substituto pode ser hierarquicamente inferior ao substituído na função que the assegurou essa prerrogativa, mas não o é no momento em que ocorre a substituição.

10. Se é certo que fieqũentemente se denominam delegação legislativa e delegaçăo de poderes, indiferentemente, năo é correta a sinonímia, năo só porque há delegaçăo de poderes que nảo săo legislativos (cf. nota 8 , supra), como há delegações legislativas que nåo săo de poderes, porque se exercem dentro do próprio Legislativo (Cf. Constituiçăo Federal de 1967 , art. 55 , caput, da primitiva redaçăo, $e$ art. 52 , caput, da atual, quando as leis delegadas podem ser elaboradas por comissăo do Congresso Nacional ou de qualquer de suas Casas. Vale dizer, há delegaçăo de do âmbito do mesmo Poder).

11. Năo âmo Poder).

totalmente injustifivoco (cf. ANDRÉ HAURIOU, artigo e revista cits., p. 473), embora de outorga injustificável, de se pretender que a competência do Executivo, nos casos gislativa. Na constitucional para baixar decretos-leis se constitui em delegação le. mente, ainda que possa sujeitar-se competência legislativa deferida o é originariaFederal de 1967 possa sujeitar-se ao referendo do Legislativo (V. Constituiçăo Federal de 1967, na redaçắo em vigor, art. 55, § 1.\%). E parcela do Poder Legislativo também em sentidonferida pela Constituiçăo, pelo que o ato assim baixado é lei nha originariamente, formal. Só se recebe em delegaçăo a atribuiçăo que năo se tiginária de lei forma vale dizer, só há delegaçăo quando inexiste competência ori-

12. A menos de lei formal para a prática do ato.

delegantes se situam em delegaçăo de poderes, quando os órgăos ou autoridades ridades delegados.

R. Serv. Públ., Brasília, 108 (1): jan/abr. 1973 
5. Como comumente se entende, a natureza jurídica da delegação é de uma autorização. ${ }^{13} \mathrm{E}$ o agente ou órgão que a recebe age como se essa competência delegada lhe fosse originariamente conferida, isentando-se o delegante, ao contrário do que ocorre no mandato, ${ }^{14}$ de qualquer responsabilidade pelo ato praticado em razão da delegação. ${ }^{15}$

A transferência de competência, ainda que com reservas, alça o delegado à posição do delegante no que concerne àquelas atribuições, pelo que nenhuma responsabilidade se atribui ao delegante pelo ato do delegado, que não o representa, respondendo este pessoalmente perante a administração, embora esta se obrigue em relação a terceiros prejudicados, pelo princípio da responsabilidade objetiva, o que é outro caso. ${ }^{16}$

A delegação, como autorização, pode ser feita: a) com reserva de competência, isto é, o delegante também deixa a si a prática do ato objeto da delegação, agindo concorrentemente com o delegado; b) sem reserva, quando as atribuições objeto da delegação são totalmente transferidas ao delegado.

Ocorra a delegação com reserva ou sem ela, dada a sua natureza jurídica de autorização, é ato discricionário, razão por que pode ser revogada, pelo delegante, a qualquer momento

13. Cf. MARCELLO CAETANO, ob. e vol. cits., n.0 100, p. 220; FLAMINIO FRANCHINI, ob. cit., ps. 115 e 156: "Ém atençăo ao ato que dá origem à delegaçăo, deve, pois. concluir-se que se trata de uma autorizaçăo administrativa particular". E, mais adiante (p. 188):..." 0 ato de delegaçăo se inclui na categoria geral das autorizaçōes administrativas".

14. FLAMINIO FRANCHINI, ob. cit., assim conceitua a deferença: "Um primeiro elemento é constituido do objeto. Na delegaçăo de direito público, diferentemente da representaçăo, trata-se como já se esclareceu, de funçōes, isto é, de poder, que vem exercido năo por um interesse próprio ou exclusivamente próprio, mas por um interesse de outrem, ou, como se diz, por um interesse objetivo" (ps. 36 e 37 ).

15. "Em direito privado, uma pessoa que gere seus próprios negócios pode confiar esses cuidados a um mandatário: se o mandatário gere mal, o mandante será o único a suportar-lhe as conseqüencias danosas, mas, em direito público, o funcionário não pode dar, a um terceiro, mandato para executar suas funçס̄es, porque săo os negócios de outrem, da coletividade, que ele gere e que toda essa coletividade sofreria por uma má gestăo do mandatário. O funcionário foi escolhido intuitu personae, em conseqüência, mais freqủentemente, de exames ou concursos destinados a determinar o seu valor profissional. Foi a ele pessoalmente que a autoridade competente confiou a gestão dos negócios públicos. E, pois, inadmissivel que ele, por sua própria iniciativa, se substitua por um terceiro.

O principio é, pois, que as competências năo podem ser objeto de um contrato de mandato.

Como, no entanto, é necessário prever que pode ser impossivel a um funcionário, em certos casos, exercer ele próprio todos os seus poderes e que a funçăo deve ser exercida de qualquer modo, outros processos tiveram de ser imaginados para suprir o mandato. São a delegaçăo e a suplência legal" (MARCEL WALINE, Traité Elémentaire de Droit Administratif, Paris, 1950, 5.a ed., p. 536).

16. Cf. Const. Federal, art. 107, caput. A pessoa juridica de direito público, de que o delegado é agente, responde pelos danos que este, no exercicio de suas funções, causar a terceiros, năo tendo nenhuma responsabilidade, no caso, o delegante, cabendo ainda ação regressiva da pessoa de direito público contra o delegado, se agiu este com culpa ou dolo (Const. Federal, art. 107, parágrafo único). 
e sem invocação de motivo. ${ }^{17}$ Também, por igual, mesmo nos casos em que se verifica delegação sem reserva, não dese. jando o delegante, de um modo geral, revogar a delegação, pode chamar a si o caso, praticando o ato por avocação. ${ }^{18}$

Como as atribuições transferidas pelo delegante ao delegado colocam este, quanto à competência para a prática de tais atos, em pé de igualdade com aquele, há de se indagar, como o faz FRANCHINI ${ }^{19}$ : a) pode o delegado revogar ou suspender os atos do delegante, praticados anteriormente à delegação?; b) pode o delegado revogar atos por ele praticados por força da delegação, enquanto no uso dela?, e c) pode o delegante revogar o ato do delegado na pendência da delegação?

As três indagações responde FRANCHINI afirmativamente. A primeira, tendo em vista a igualdade de competência, quanto à matéria, entre o delegante e o delegado; à segunda, evidentemente, com maior razão, por ser ato próprio do delegado, e, finalmente, em relação à terceira e última, por ser o delegante, em geral, superior hierárquico do delegado.

Quanto à primeira, não nos parece com razão FRANCHINI an reconhecer no delegado competência para revogar 0 ato anterior à delegação, praticado pelo delegante. E inexiste essa competência porque, se é certo que ao delegado se transferiram as atribuições da espécie, também não é menos exato que essa delegação é ato discricionário, restando sempre a competência do delegante para avocar a decisão, ainda que haja transferido suas atribuições sem reserva. ${ }^{20}$ Esta, precisamente,

17. Como exemplo do que se firma no texto, pode citar-se a delegaçăo administrativa do Presidente da República aos Ministros de Estado e dirigentes de entidades da Administração Centralizada e Descentralizada para declarar a desnecessidade de cargos públicos, na forma da Constituiçăo Federal, autorizada pelo Decreto-lei $n$ o 489, de 4-3-1969 (art. $10^{\circ}, \S 20^{\circ}$ ), e efetivada pelo Decreto n.0 64.394, de 23-4-1969 (art. $10^{\circ} \S 2 .{ }^{\circ}$, revogada expressamente pelo Decreto n. ${ }^{\circ} 65.764$, de 2-12-1969 (art. 1.0).

Cf., também, sobre a revogaçăo ad libitum do delegante, CARLOS GARCIA OVIEDO e ENRIQUE MARTINEZ USEROS, Derecho Administrativo, 9.a ed., Madrid, 1968, vol. I, p. 567; FRANCHINI ob. cit., p. 193, por esta forma se manifesta: "Com respeito particularmente à possibilidade de revogaçăo do ato de delegação, pode afirmar-se que, sob o-ponto-de-vista subjetivo, é necessário reconhecer ao

18. "O fato de o delegante ter permitido ao delegado o exercicio dos poderes năo o
priva destes: priva destes: o delegante continua a ser competente, cumulativamente com o delegado. Mas quando queira exercer a sua competência deve o delegante avocar - caso, de modo a evitar a existência de duas decisōes concorrentes. Isto é: de. em em que houve delegaçăo, mas, ob. cada caso, só um deles pode exercer a competência" (MARCELLO C. CAETANO,

19. Ob. cit., ps. 194 a 196

20. Cf. nota 18 , supra.

R. Serv. Públ., Brasília, 108 (1): jan/abr, 1973 
é uma das diferenças entre delegação e substituição, porquanto, nesta, não haveria dúvida sobre a competência revocatória do substituto em relação ao ato do substituído, que não lhe é superior hierárquico quando o substituto lhe esteja substituindo. Como o delegado, na delegação administrativa, é hierarquicamente inferior ao delegante, não poderia nunca revogar o ato deste, praticado em decorrência de identidade de atribuições. A solução dada a esta indagação por FRANCHINI é, de certo modo, contraditória com a que ele, acertadamente, dá à terceira, reconhecendo a prerrogativa do delegante em revogar o ato do delegado na pendência da delegação. Se reconhece esta competência do delegante, como justificaria igual poder sobre ele do delegado? O que legitima a interferência do delegante, revogando o ato do delegado, é a sua supremacia hierárquica, o que não ocorre em favor do delegado.

MARCELLO CAETANO, ${ }^{21}$ a propósito da questão assim opina: "A solução do problema parece dever procurar-se antes na razão das posições relativas de delegante e delegado. O delegante é aquele órgão ao qual a lei confere principal e diretamente a competência, como responsável pelas funções que Ihe estão atribuídas. $O$ delegado, quer a delegação esteja implícita na natureza do cargo, quer resulte de ato de delegação, é um auxiliar do delegante destinado a descongestionar ou desconcentrar as tarefas dele, mas sem o privar das responsabilidades da função. Desse modo, ao delegante deve sempre ser reconhecido um direito de vigiar o uso dos poderes delegados, um poder de superintendência (independentemente da hierarquia), sem o que a delegação implicaria a alienação dos poderes e até poderia criar a subversão das situações. Isto é, não há relação jurídica de hierarquia, mas existe uma supremacia política que dá prevalecimento à vontade do delegante.

Ao delegante caberá, portanto, o poder de revogar os atos do delegado, como se fosse superior hierárquico dele, visto serem as mesmas as razões pelas quais tem de reconhecer-se a superintendência do delegante ou do superior.

Mas essas razões impedem que se admita a competência do delegado para revogar os atos do delegante. É a este que incumbe dar as orientações necessárias para o desempenho das funções, traçar as diretrizes da interpretação das leis com as quais o delegado deverá informar-se".

21. Ob. e vol. cits., n. 0 216, ps. 492 - 493.

R. Serv. Públ., Brasília, 108 (1): jan/abr. 197:3 
Mais adiante, assim termina o eminente jurista português e Chefe de Estado do país amigo: "O delegado não pode revogar os atos do delegante sem pôr em choque a posição deste como órgão normal e plenamente competente para o desempenho da função a que pertencem os poderes delegados".

7. A mudança dos titulares, quer se trate do delegante ou do delegado, importaria em caducidade da delegação?

A matéria é controvertida, entendendo alguns que, embora o agente tenha sido escolhido intuito personae, em se tratando de relações funcionais, a mudança dos titulares, quer seja 0 delegante ou o delegado, não importa em extinção da delegação. MARCELLO CAETANO, ${ }^{22}$ embora se incline nesse sentido, esclarece que a regra do direito português é pela caducidade.

Não vemos como acolher-se a caducidade da delegação na hipótese de mudança dos titulares, impondo-se ato revocatório expresso para extinguir-se a delegação. É que a relação jurídica entre os titulares, mesmo ocorrendo a mudança, é sempre entre um superior e o inferior hierárquico, o que faz presumir continuidade de confiança, do contrário não se manteria a subordinação.

8. Quid, no que tange à subdelegação? Poderia o delegado transferir a seu subordinado as atribuições recebidas em delegação, ou lhe é vedada essa subdelegação?

Vigorando as mesmas regras para a subdelegação que as incidentes sobre a delegação, ${ }^{23}$ como só há esta se ocorreu autorização legislativa formal, segue-se que a subdelegação só se verifica se houver dispositivo legal admitindo-a, nos casos taxativamente especificados. No silêncio da lei, entende-se vedada a subdelegação. ${ }^{24}$

Segundo informa MARCELLO CAETANO, no direito português se acolhe a subdelegação, desde que o delegante autorize o delegado a transferi-las ao subdelegado, ${ }^{25} \mathrm{com}$ o que a autorização legislativa só seria exigível para a delegação, na qual poderia o delegante permitir a subdelegação. Mas há de acrescentar-se: se a lei o permitir.

22. Ob. $\theta$ vol. cits., n. $0^{100, \text { p. } 220 .}$

23. ALCINO PINTO FALCÃO, Repertório, cit., verbete Delegaçăo, p. 155

24. Sobre o tema, cf. FRANCHINI, ob. cit., ps. 176 e 177.

25. Ob. cit., n. ${ }^{\circ} 100$, p. 222.

R. Serv. Públ., Brasília, 108 (1): jan/abr. 1973 
A subdelegação nada mais é do que uma delegação da delegação e, como tal, não poderia verificar-se sem suporte legal, ao nuto do delegante, que só tem essa faculdade quando a lei o autoriza e para as atribuições que especifica.

9. São requisitos da delegação, de um modo geral: a) pre. ceituação constitucional ou de lei ordinária que a autorize, segundo a natureza da delegação; b) a competência, originária e excludente de qualquer outro, do órgão ou autoridade delegante, que outorga suas atribuições ao órgão ou autoridade delegada, e c) a forma expressa do ato de delegação. ${ }^{26}$

De um modo geral, todos os atos que importam em atribuições substanciais do órgão ou autoridade são insuscetíveis de delegação, devendo, assim, por ele ou ela ser exercido diretamente. FRANCHINI (ob. cit., pág. 182 a 184) indica os atos que, pela sua natureza, não seriam suscetíveis de delegação. São eles: a) os que, pela sua amplitude e pela esfera de eficácia, exorbitariam da competência da autoridade a quem se desejaria outorgar a delegação; b) os atos que importem em atividade de controle sobre a autoridade a que seriam delegados; c) os atos que exigem procedimento especial ou uma forma solene, que não poderiam ser observados se se procedesse à delegação; d) as atribuições mais importantes conferidas a uma dada autoridade e que the caracterizam, de certo modo, a essência e a posição no âmbito da administração.

Se é assim, como se delegam, verbi gratia, ao Poder Executivo as atribuições essenciais de outro Poder, o Legislativo, através das leis delegadas?

Diríamos que a competência constitucional só pode ser delegada com reservas, isto é, o delegante mantém consigo as atribuições que delegou, exercendo-as concomitantemente com 0 delegado. Assim, poderia dizer-se: as atribuições constitucionais são, em princípio, indelegáveis, quando caracterizam as funções específicas do delegante, a menos que essa função

26. MARCELLO CAETANO, ob. e vol, cits., n..$^{\circ} 100$, ps. 219 e 220 , arrola os seguintes requisitos da delegaçăo: "a) lei que a permita; b) dois órgăos ou um órgăo e um agente da mesma pessoa coletiva de direito público indicados pela lei, dos quais um normalmente competente (o delegante) e outro eventualmente competente (o delegado); c) a delegaçăo propriamente dita, isto é, o ato pelo qual o delegante autoriza oxercicio dos poderes pelo delegado, salvo os casos de delegação implicita". 
precípua em termos constitucionais seja delegada sem que se prive o delegante de idênticas atribuições, concorrentemente com o delegado.

Houve sempre, em nosso Direito, as maiores reservas relativamente às delegações de competência, não só quando estas extravasam do âmbito de um Poder para o outro, constituindo as delegações de poderes, como até mesmo, no que concerne às delegações dentro do mesmo Poder, cuja prática é largamente adotada no Direito Administrativo alienígena.

10. A separação rígida de poderes, que obteve formulação expressa na Constituição de 1934 (art. $3 .^{\circ}$ § $1 .^{\circ}$ ), desapareceu totalmente sob o regime instituído em 10 de novembro de 1937 , de inspiração totalitária, quando, desaparecendo o Congresso Nacional, as funções legislativas e executivas se concentraram nas mãos do Chefe do Governo, que o exercia ditatorialmente. Com a restauração democrática, ocorrida em 1946, como reação do Parlamento, temeroso de nova arremetida antidemocrática, voltou-se à fórmula de separatismo rígido, ${ }^{27}$ que mereceu, entre nós, as maiores censuras de destacados cultores do Direito Público, 28 sendo a delegação de poderes uma necessidade por todos reconhecida.

Quanto às delegações administrativas, nada dispunham as Constituições anteriores, só passando a haver norma constitucional expressa a respeito a partir da Carta Política de 1967, desde a sua primitiva redação, ${ }^{29}$ mantida com pequenas alterações pela Emenda Constitucional n. 1 , de $1969^{30}$. Disse-se, então: "A lei poderá autorizar o Presidente a delegar aos Ministros de Estado, em certos casos, as atribuições mencionadas nos itens VI, XVI e XX" (isto é, "prover os cargos públicos federais, na forma desta Constituição e das leis"; "autorizar brasileiros a aceitar pensão, emprego ou comissão de governo estrangeiro", e "conceder indulto e comutar penas, com audiência dos órgãos instituídos em lei" - redação primitiva da Constituição de 1967). Na redação em vigor, mantêm-se as mesmas atribuições como suscetíveis de delegação pelo Presidente da República. aos Ministros de Estado e, já agora, a outras autoridades, acrescentando a autorização para delegar competência

27. Const. Federal de 18 de setembro de 1946, art. $36, \S 2 .^{\circ}$.

28. Cf., ao propósito, VICTOR NUNES LEAL, Delegações Legislativas, R.D.A., vol. V,

29. Art. 83, parágrafo único.

30. Art. 81, parágrafo único.

R. Serv. Públ., Brasília, 108 (1): jan/abr. 1973 
na extinção dos cargos públicos e a de dispor sobre a estruturação, atribuições e funcionamento dos órgãos da administração federal (que não constituiam competência conferida ao Presidente da República na primitiva redação da Carta Política de 1967).

11. Dentro desse princípio que a Constituição estabelecera com a possibilidade de outorga, pelo Presidente da República, de delegação administrativa de algumas atribuições constitucionais, com exclusão, a contrario sensu, como evidente, das outras, que são indelegáveis, o Decreto-lei n. 200 , de 25 de fevereiro de 1967, estatuiu:

"Art. 6. - As atividades da Administração Federal obedecerão aos seguintes princípios fundamentais:

IV - Delegação de Competência.

Art. 11 - A delegação de competência será utilizada como instrumento de descentralização administrativa, com o objetivo de assegurar maior rapidez e objetividade às decisões, situando-as na proximidade dos fatos, pessoas ou problemas a atender.

Art. 12 - É facultado ao Presidente da República, aos Ministros de Estado e, em geral, às autoridades da Administração Federal, delegar competência para a prática de atos administrativos, conforme se dispuser em regulamento.

Parágrafo único - $\mathrm{O}$ ato de delegação indicará com precisão a autoridade delegante, a autoridade delegada e as atribuições objeto de delegação.

Art. 173 - Os atos de provimento de cargos públicos ou que determinarem sua vacância, assim como os referentes a pensões, aposentadorias e reformas, serão assinados pelo Presidente da República, ou, mediante dele- 
gação deste, pelos Ministros de Estado, conforme se dispuser em regulamento". ${ }^{31}$

12. Por força dessas medidas de desconcentração, aliviaramse grandemente as autoridades superiores de tarefas burocráticas, que só contribuíam para uma sobrecarga de trabalho, em prejuízo das preocupações com problemas de maior transcendência.

A descentralização, de um lado, e a desconcentração, de outro, permitirão que os encargos entregues ao Poder Público sejam satisfatoriamente desempenhados, sem que se congestione a atividade burocrática, que não pode ser elidida porque imprescindivel, mas que assim será mantida em compasso que não perturbe o desenvolvimento do País.

O extraordinário progresso das ciências exatas, ao determinar verdadeira revolução em todas as atividades humanas, não poderia deixar de incrementar também as ciências sociais, que, ou acompanhariam o ritmo desse desenvolvimento, ou ficariam à janela, vendo o tempo fugir. como a musa da canção popular...

31. Regulamentado pelo Decreto n. 60.740 , de 23-5-1967.

R. Serv. Públ., Brasilia, 108 (1): jan/abr. 1973 